\title{
INFORMAÇÃO ESCOLAR: O SISTEMA ESTADUAL DE REGISTRO ESCOLAR (SERE) DO PARANÁ
}

\author{
Selma Maria Costa de Oliveira (UFPR, Brasil) smkbreda@gmail.com \\ Sônia Maria Breda (UFPR, Brasil) selmacolive@gmail.com
}

Resumo: Estudo sobre a informação escolar com foco no Sistema Estadual de Registro Escolar (SERE) do Paraná. Objetiva analisar dados e informações do sistema, as relações estabelecidas entre os usuários e sua visão do SERE. A partir de referencial teórico relacionado a programas de Tecnologias de Informação e Comunicação implementados na escola pública estadual paranaense e sistemas de informação, realiza trabalho de campo em doze escolas da rede, localizadas nos municípios de Curitiba, Piraquara e Colombo, PR., com aplicação de questionários às equipes de secretaria, de pedagogos e de professores. Os principais resultados indicam um sistema que dá suporte à tomada de decisão, mas requer melhoramento na concepção dos relatórios e na disseminação de dados e informações disponíveis, sendo reconhecido o seu potencial para maior contribuição para a finalística da escola.

\begin{abstract}
Study on school information focusing on State's System of School Registration (SSSE) at Paraná. It aims to analyze data and information systems, the relations established between users and their vision of SSSE. From a literature review related to Information and Communication implemented in public school of Parana and information systems, this paper conducts a fieldwork in a networkof twelve schools, located in the cities of Curitiba, Piraquara and Colombo, at the state of Parana, with application questionnaires on the secretarial teams, educators and teachers. The main results indicate a system that supports decision making, but requires improvement in the design of reports and dissemination of data and information available, being recognized its potential for greater contribution to the school finalistic.
\end{abstract}




\section{Introdução}

No ambiente da gestão escolar, dados e informações dos estudantes colhidos na educação básica, transcursam e se complementam no cenário pedagógico e organizacional. Processados, arquivados e recuperados influem mais intensamente sobre os processos e decisões da gestão educacional. Dados e informações antes restritos à escola passam a circular entre as escolas e entre a unidade escolar e o órgão de administração central, oriundos da intervenção dos educadores, motivados pela modernização da gestão educacional e escolar.

Todo sistema de informação deve servir às finalidades da instituição para o qual foi desenvolvido, seja como resultado de ações procedimentais pré-estabelecidas em processos gerenciais ou incrementado a partir de ações espontâneas de aperfeiçoamento estabelecidas a partir de seus usuários. Um sistema de informação de registro escolar interfere no processo de registro de dados, arquivamento e emissão de documentos com padrão próprio de uma gestão documental. Gera relatórios que podem servir para a tomada de decisão coletiva destinada ao replanejamento organizacional, monitoramento e revisão do trabalho escolar, a partir da percepção do modo de desenvolvimento do processo ensinoaprendizagem.

Esta pesquisa estuda a informação disponibilizada no Sistema Estadual de Registro Escolar (SERE) tendo em mira a análise de dados e informações do sistema, as relações estabelecidas entre os usuários e sua visão do sistema, ativo em todas as unidades escolares públicas estaduais paranaenses, acessível também às escolas públicas municipais e a entidades privadas de educação básica.

A trajetória metodológica do estudo aqui sintetizado partiu do referencial teórico relacionado a programas de Tecnologias de Informação e Comunicação implementados para o gerenciamento dos processos na Escola Pública Estadual Paranaense e os Sistemas de Informação para a escola e trabalho de campo com a aplicação de questionários às equipes de secretaria, de pedagogos e de professores de doze escolas da rede, localizadas nos municípios de Curitiba, Piraquara e Colombo.

2. Dos programas em tecnologia de informação e comunicação no âmbito educacional ao sistema de registro escolar paranaense

Há um considerável número de programas estatais no país destinado à área educacional. Implantados pelos órgãos públicos, traduzem a legislação.

Tono (2011) considera que entre as ações do Estado está a de informatizar ambientes públicos, assegurado acesso à informação pela CR / 88, inciso VII do Artigo $5^{\circ}$, por meio de programas e projetos para a informatização dos espaços escolares em todos os níveis de ensino. Silva (2011, p.532) crê que a formulação de políticas públicas para 
minimizar tanto a exclusão digital como a social "... deveria ser prioridade de um estado que pretende diminuir as distâncias sociais existentes no país". Cantini afirma que "As tecnologias estão disponíveis nas escolas públicas por meio de programas públicos" (2008, p. 115).

À medida que os equipamentos informáticos começaram a chegar às escolas, a partir dos programas federais como o Programa Nacional de Informática na Educação (PROINFO) Programa de Extensão e Melhoria do Ensino Médio (PROEM), geraram mudanças na estrutura organizacional da gestão da informática na educação paranaense.

No domínio estadual paranaense, vigora o Programa Paraná Digital (PRD), resultado de uma parceria entre a Secretaria de Estado da Educação (SEED), a Universidade Federal do Paraná (UFPR), a Companhia de Informática do Paraná (CELEPAR) e a COPEL (Companhia de Energia Elétrica do Paraná), além do apoio da Secretaria de Estado da Ciência e Tecnologia (SETI). Foi lançado em 2003, assentado sobre a inclusão digital da comunidade escolar em três pilares fundamentais:

- Repasse de equipamentos e estabelecimento de conectividade em todas as escolas públicas estaduais;

- Criação e formalização de um canal institucional colaborativo Portal Dia a dia Educação - para produção e publicação de materiais didáticos digitais em ambiente $w e b$;

- Formação de educadores para uso pedagógico desses recursos utilizando a plataforma Linux de software livre. (PARANÁ, 2010, p. 68)

A estruturação de um novo ambiente pedagógico dotado de equipamentos informáticos com recurso de internet representou um marco para as escolas públicas estaduais paranaenses, sobretudo por estar associado ao Portal Dia a Dia Educação que divulga as informações institucionais, incluídos os dados das escolas, e serviços dedicados a alunos, educadores, gestores e comunidade escolar. Os usuários do Portal são providos de informações que dão suporte “... ao desenvolvimento de atividades corporativas, ao processo decisório [...] visando à melhoria da atuação profissional" (MOLINA, 2010, p. 159). Os serviços informáticos são desenvolvidos e mantidos pela Companhia de Informática do Paraná (CELEPAR), que possibilita o acesso às informações institucionais por meio de software livre.

A intenção do PRD era propiciar a professores e alunos o uso pedagógico das Tecnologias da Informação e Comunicação. Com o processo de implementação do programa, novos recursos foram se somando, entre eles:

a TV Multimídia, a distribuição de pen drives, a TV Paulo Freire e o Sistema de Registro Escolar para Web (SERE Web), (friso nosso) [...] A UFPR desenvolveu e disponibilizou soluções de software livre Linux para os laboratórios das escolas, que rodam no modelo Four Head [...] A COPEL faz chegar a 
todas estas escolas a conectividade de banda larga, através de fibras ópticas, via rede satélite, e via rádio (PARANÁ, 2010, p. 115).

Tachizawa e Andrade (2003) esclarecem que as Tecnologias de Informação e Comunicação em organizações públicas aplicam-se para a conversão dos tradicionais processos convencionais em papel para processos digitais liberando assim as pessoas para atividades mais importantes e reduzindo o fluxo de papeis e deslocamento de pessoas, a eliminação de funções isoladas estabelecendo circuitos ágeis de fácil monitoramento de processos, a criação do acervo organizacional para consequente compartilhamento e a fluidez da comunicação interna e externa para que as decisões sejam tomadas no tempo certo.

No sistema educacional, Zuccarone (2011) detectou a falta de tecnologias voltadas à gestão, apontando que existe uma grande quantidade de software de administração escolar, que inadequados à demanda das reais necessidades da escola, "estão muito distantes de contemplar os objetivos transformadores que requer o sistema educacional brasileiro" (idem, p. 60). Zuccarone frisa a meta número 2.1 do Plano Nacional de Educação 2011-2020 "Criar mecanismos para o acompanhamento individual de cada estudante do ensino fundamental" (2011, p.34).

$\mathrm{O}$ autor destaca que todas as informações geradas pela tecnologia aumentam o poder de decisão do educador nos "casos de dificuldade individual de cada aluno na rede, conhecendo e compreendendo as causas/os problemas [...] os eventuais motivos que levaram a criança a apresentar uma ou outra dificuldade em algum momento do seu processo natural de aprendizagem" (ZUCCARONE, 2011, p. 61). Sistemas específicos são desenvolvidos para armazenar e tratar dados sobre a vida escolar do aluno, englobando ainda outras atividades necessárias para subsidiar o sistema de informação escolar. Este integra dados das áreas administrativas existentes na escola englobando recursos financeiros, materiais, pedagógicos e humanos. Em geral, estes programas são personalizáveis e possibilitam informações aos pais através da internet. Permitem que as notas sejam digitadas remotamente pelos professores, além de serem, disponibilizados em módulos, conforme o destino da informação. Há controle de frequência, entrada e saída de estudantes e outros profissionais por cartão magnético e catraca eletrônica. A comunicação com a família é potencializada pelo correio eletrônico ativado a cada ocorrência pedagógica.

Os gestores da escola pública estadual paranaense contam com um sistema informacional que atende a gestão de dados e de informação referentes aos dados ou registros escolares. Trata-se do Sistema Estadual de Registro Escolar - SERE disponibilizado aos gestores da escola pública, no link "gestores", e designado "sistemas de registro" de acesso possível pelo portal institucional.

Originado em 1993 a partir do Sistema Escola, com Sistema Operacional MS-DOS, época em que as unidades escolares não estavam 
providas de equipamento informático, implantado entre 1994 e 1999, hoje em dia é designado como SERE off line.

Para Caires (2010), o SERE destinava-se a coleta, tratamento e disseminação de informações para o planejamento e gerência do processo organizacional, tendo como objetivo no âmbito:

- educacional: compor um Banco de Dados Central dos estudantes da rede pública do Paraná, subsidiar o planejamento organizacional da rede pública estadual e viabilizar a comunicação das escolas com o sistema central;

- escolar: agilizar os procedimentos da secretaria escolar, registrar as rotinas relativas à vida legal do estudante tais como cadastro, matrícula, transferência, evasão, aproveitamento escolar e outros e manter o registro dos atos legais da instituição de ensino, suas matrizes curriculares e organização de turmas por número de alunos, turno e período letivo.

Com o aprimoramento e a aquisição de equipamentos, outros recursos foram acoplados, como a internet. Para além da informatização dos dados, pela união da equipe da CELEPAR e do Instituto de Desenvolvimento Educacional do Paraná (FUNDEPAR), foi desenvolvido entre os anos de 2003 e 2004 o SERE na web (Caires, 2010). Disponibilizado em plataforma livre a partir de 2005, passa a ser designado SERE-Web, SERE on line ou ainda, Sistema de Gestão Escolar.
Em 2012, o SERE além do Módulo Sistema Escola, possui “... uma base gerencial onde armazena, trata e distribui as informações conforme a demanda, tanto a nível Estadual como Federal e Municipal" (PORTAL DIA A DIA, 2012).

O SERE on line em termos operacionais na escola, tornou possível o acesso remoto do Núcleo Regional de Educação, a agilidade no lançamento de dados, a facilidade na emissão de documentos-padrão dos estudantes e a qualidade visual da informação.

\section{Resultados}

Para a compreensão do funcionamento do SERE, pelo seu conteúdo destinado à organização seriada do ensino fundamental e médio, realizou-se análise na plataforma diretamente no sítio, de acesso próprio observado a estrutura do Sistema em setembro de 2012.

Foram colhidas as impressões dos usuários doze escolas públicas estaduais, nove em Curitiba, uma em Piraquara e duas, situadas no município de Colombo. Em cada instituição foram entregues seis questionários, dois para serem respondidos pela equipe de secretaria, dois para a equipe de pedagogos e dois para o corpo docente. A amostra compôs-se, portanto, de vinte e dois secretários e/ou auxiliares de secretaria, vinte pedagogos e vinte professores, atuantes em escolas que ofertam o Ensino Fundamental - anos finais e Ensino Médio. Dos setenta e dois questionários distribuídos, retornaram à pesquisadora sessenta e dois, ou 
seja, oitenta e seis por cento.

Revela-se que em decorrência das atribuições específicas de cada grupo de respondentes no ambiente escolar, os questionários foram individualizados em três formatos, levando-se em consideração a familiaridade com o Sistema.

\subsection{A visão da estrutura do SERE}

A partir da análise foram identificadas três áreas que se integram e denominadas registro escolar, planejamento escolar e estrutura e funcionamento da escola.

A gestão dos dados permeia todo o processo pedagógico, do início ao fim, desde validar a entrada do aluno na escola, ao registrar sua permanência e desempenho em cada disciplina cursada, até o armazenamento e emissão de documentos relativos à história de escolarização do aluno.

O SERE, a partir da secretaria de escola, permite a emissão de documentos padronizados dos estudantes e de relatórios referentes aos dados processados, integradas as áreas designadas como registro escolar, planejamento escolar e estrutura e funcionamento. Uma ação obrigatória do secretário ou auxiliar, além das mencionadas, corresponde à coleta de dados para o Censo Escolar pela atualização do cadastro da escola, funcionários, docentes, turmas e uso de transporte escolar atendem aos requisitos do sistema educacional.

A gestão da informação na escola volta-se da coleta de dados aos relatórios emitidos e sua potencial utilização pela equipe gestora, capaz de redirecionar o trabalho escolar, caso o pedagogo, juntamente com o diretor e o secretário da escola articulem conscientemente esta possibilidade em colaboração com os professores e com os estudantes.

Por mais que a escola exista e permaneça como um espaço social fundamental para as crianças e jovens, da análise quadro a quadro do SERE on line, dados e informações que possibilitem uma análise diferenciada do estudante em função do seu desenvolvimento pessoal, seja do ponto de vista biológico, emocional, social ou cultural é restrito.

\subsection{A visão do usuário do SERE no contexto escolar}

Para o gestor escolar do SERE, secretário (a) e/ou auxiliar, responsável pela coleta de dados e sua intermediação à equipe pedagógica e diretor (a), foi solicitado o grau de concordância quanto à qualidade dos dados e informações do SERE para o atendimento das funções de registro, a sua utilização pelo e para o campo pedagógico, a existência de possíveis lacunas informacionais para a concretização dos objetivos educacionais e os pontos positivos e a melhorar do sistema informático. 


\section{GRÁFICO 1 - QUALIDADE DOS DADOS/INFORMAÇÕES DO SERE}

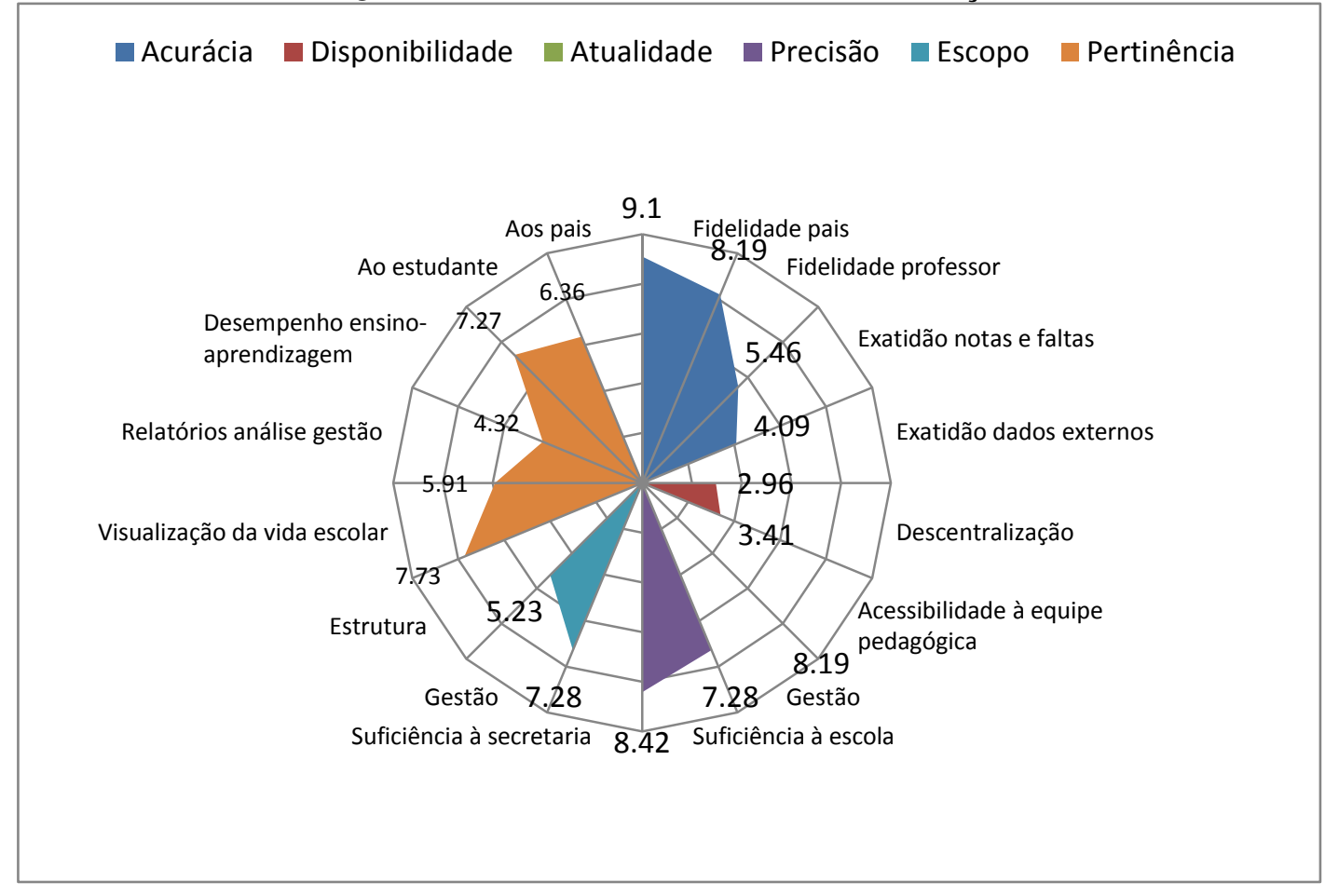

Fonte: A autora (2012)

A qualidade da informação do SERE foi considerada satisfatória pelo seu gestor no contexto escolar, restrito ao grupo amostral, quanto aos requisitos de qualidade, disponibilidade, atualidade, precisão, escopo e pertinência, tomados de Sordi (2009). No entanto, existe contraposição quanto à exatidão das notas e faltas, elementos da coleta de dados interna, à disponibilidade considerando que o acesso direto ao Sistema é facultado ao gestor da secretaria escolar, com repercussão na análise de dados e geração de informação aos demais componentes da equipe escolar e sua relação com a análise do desempenho ensinoaprendizagem.

Os dados/informações do SERE cabem à área pedagógica, segundo a equipe de secretaria, para apoiar a prática diária, reuniões e planejamento, da busca de dados pessoais dos estudantes e seus familiares à geração de gráficos e índices que norteiam as metas a serem alcançadas e estabelecidas a partir das notas e percentual de frequência. Determinados como contribuição para o processo educativo basicamente a gestão de dados e documental, manifestada em procedimentos padronizados na secretaria, destinada à organização do trabalho escolar e pedagógico que podem servir como elementos ao diagnóstico e reavaliação do trabalho.

Como pontos frágeis foram apontados os relatórios estatísticos para um melhor aproveitamento da equipe pedagógica e a lentidão do Sistema, diante da facilidade, praticidade e agilidade proporcionadas.

Junto ao pedagogo, participante desta pesquisa, buscou-se obter detalhes quanto à coleta $\mathrm{e}$ utilização de dados/informações provenientes 
do SERE, partindo dos elementos implicados à elaboração do perfil do estudante (gráfico 2).

Os dados pessoais e as notas dos estudantes foram indicados como os mais procurados pelos pedagogos, dados estes obtidos do SERE; o motivo de possíveis faltas do estudante e suas condições de saúde são elementos não contemplados no Sistema, assim como, as dificuldades de aprendizagem.

Evidenciada a interposição da equipe de secretaria para acesso dos pedagogos aos dados/informações do SERE, deste o boletim escolar e os relatórios com notas são os mais utilizados. Para os pedagogos os dados do SERE mostram a realidade educacional, indicam o desempenho dos discentes, propiciam reflexões e ações coletivas e reorientam o planejamento docente em metodologia, avaliação e seleção de conteúdos. Das contribuições do Sistema ao processo educativo enfatizou-se o gerenciamento da vida escolar pelos registros e o suporte ao trabalho administrativo e pedagógico da escola. Mencionadas como lacunas em dados/informações os atendimentos pedagógicos, os relativos aos estudantes com necessidades especiais, os próprios registros de classe, mas on line $\mathrm{e}$ o motivo das transferências dos estudantes.

O professor está no centro do sistema escolar embora distante do SERE. A percepção deste profissional sobre a coleta de dados sobre o estudante que possam vir a facilitar as decisões e ações são apontadas no Quadro 1.

\section{GRÁFICO 2 - ELEMENTOS PARA O PERFIL DO ESTUDANTE SEGUNDO O PEDAGOGO}

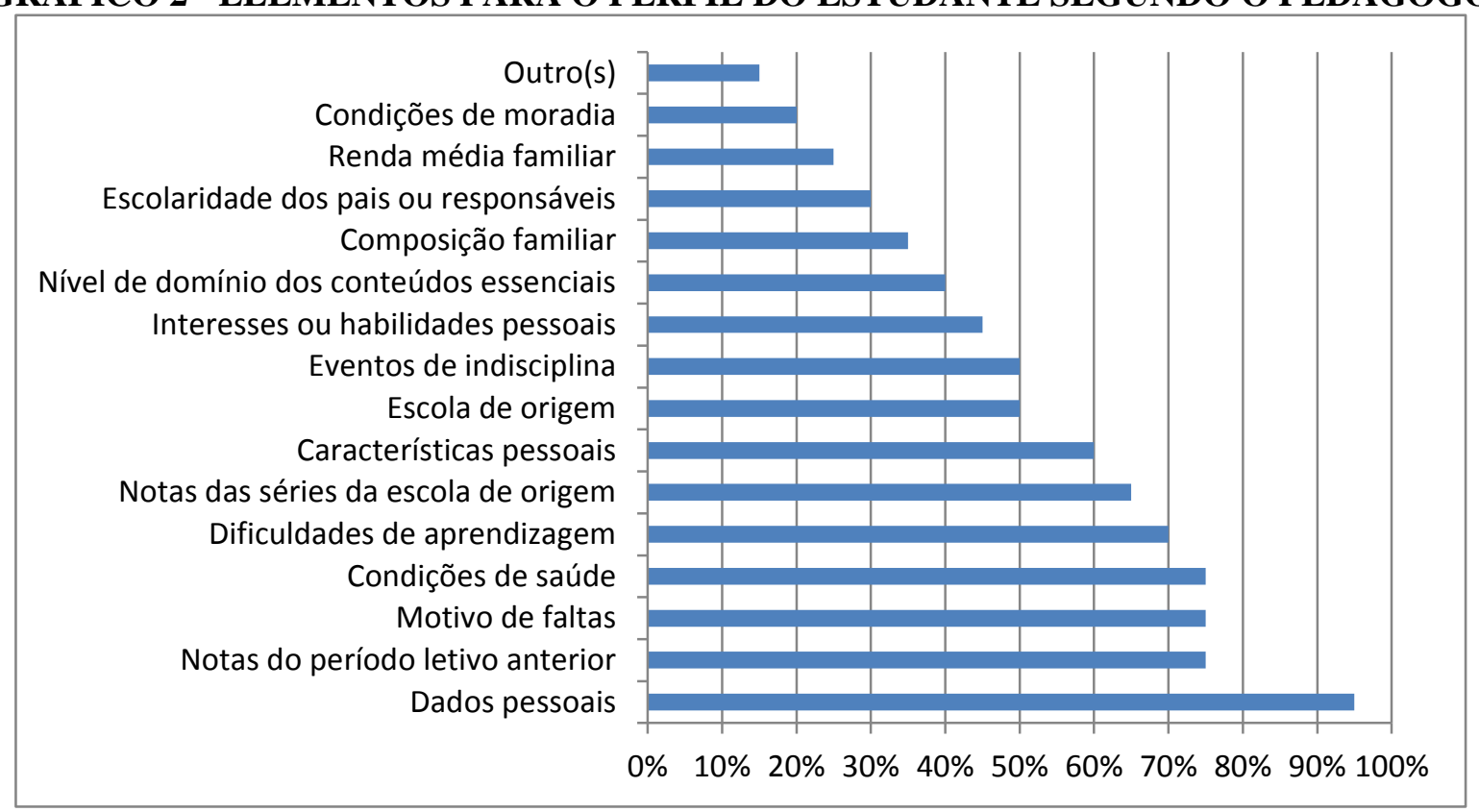

Fonte: a autora (2012) 


\section{QUADRO 1 - COLETA E DISSEMINAÇÃO DE DADOS/INFORMAÇÕES SOBRE OS ESTUDANTES, SEGUNDO O PROFESSOR}

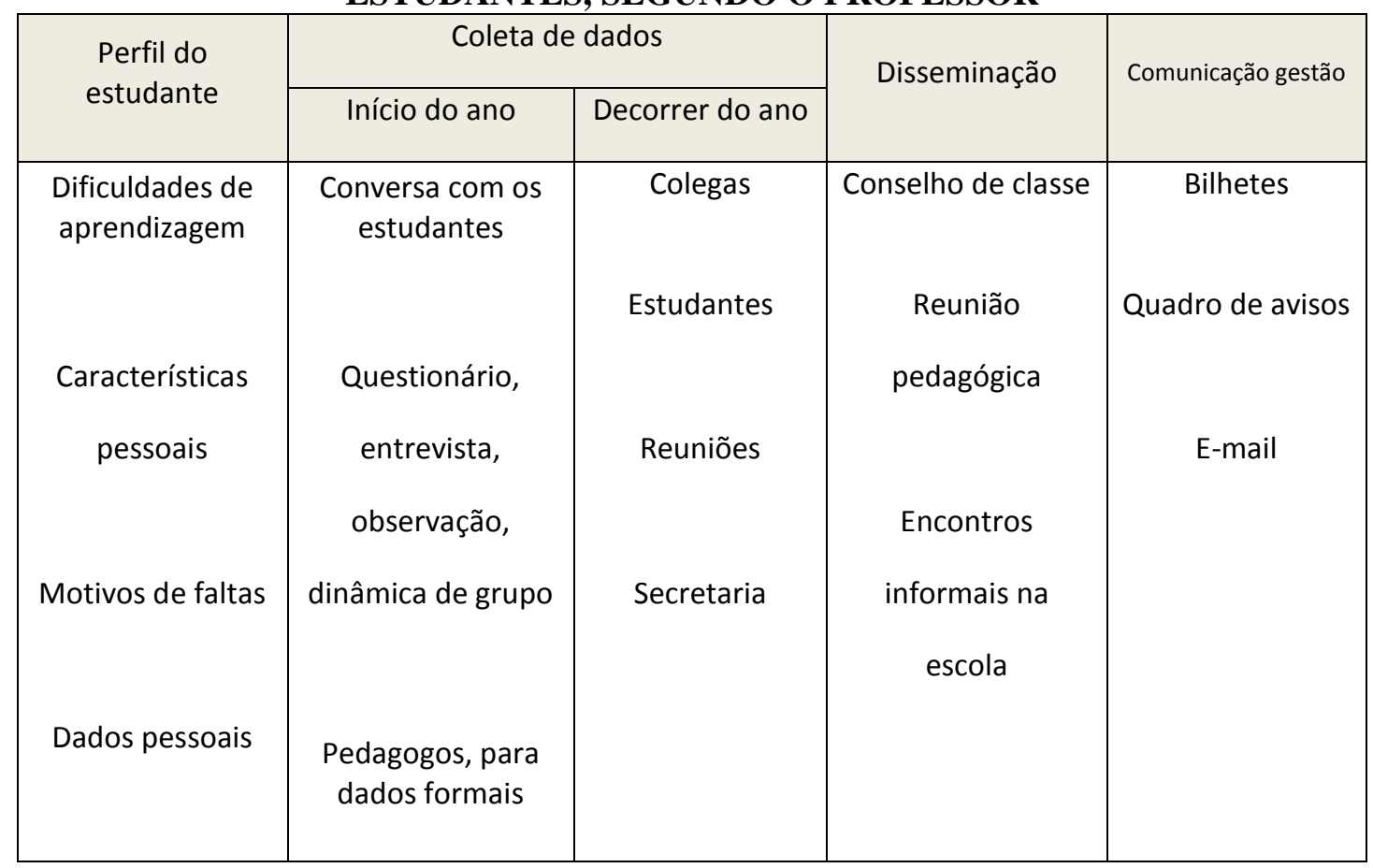

Fonte: a autora (2012)

Para o professor o SERE contribui para a organização do processo de ensino, pela documentação escolar e consulta a dados dele provindos, familiares e pessoais, além de propiciar a análise mais segura de qualidades obre o desempenho dos discentes. Revelaseque entre os depoentes professores $25 \%$ não se manifestou sobre este quesito e $5 \%$ o consideraram uma ferramenta burocrática.

\section{Considerações finais}

O SERE adquiriu um contorno diferenciado e único a partir da instalação da rede lógica. No entanto, as relações de cada protagonista escolar com o SERE são bem delineadas pelo papel que desempenham, sem que possuam a visibilidade do todo. Do caminho cíclico dos dados o sentido do Sistema está nas mãos do usuário escolar, que define qual informação é mais relevante, de que modo utilizá-la e com qual finalidade.

Os pedagogos expõem argumentos que por si só revelam a dimensão ao SERE como um autêntico Sistema de Gestão Escolar (uma das designações) e, não apenas, de gestão educacional por meio da gestão de dados e gestão documental. O Sistema carece do olhar pedagógico, restringindo a condição de uma análise diferenciada do estudante e não revelando a autêntica vida escolar. Em decorrência a equipe pedagógica recorre a dados auxiliares provindos de coleta informal: o usuário busca alternativas paralelas e complementares, partindo da sua função primordial e considerando que a gestão existe e 
mantém-se a partir do pedagógico.

No entanto, dá suporte à tomada de decisões no âmbito escolar, mostrando a realidade educacional. Com o assessoramento pedagógico suas informações propiciam reflexão e ação coletiva sobre os resultados do processo ensino-aprendizagem, possibilitando o replanejamento escolar, compreendida a organização do trabalho pedagógico.

Os professores indicam que há a disseminação parcial de dados/informações sobre os estudantes. A qualidade da informação do SERE é satisfatória pelo olhar da equipe de secretaria. Porém, os relatórios emitidos precisam ser adequados para um melhor aproveitamento no processo educativo.

Os elementos reunidos neste estudo contribuem para uma leitura parcial atual do SERE mediada por seus principais usuários, ao mesmo tempo em que levantam novas questões de pesquisa sobre o sistema.

\section{Referências}

CAIRES, R. A. Mudança organizacional do setor SERE (Sistema Estadual de Registro Escolar) do Núcleo Regional de Campo Mourão: estruturando o trabalho em equipe. 37 p. Monografia (Especialização em Gestão Pública Municipal) - Universidade Tecnológica Federal do Paraná, Curitiba, 2010. Disponível em: <http://api.ning.com/files/TRCQ454guklbB2 XmuSan7UKwjbEtyeWsg60v8L1hTySDiQu B2QYkxXDgJxiNZAyER2FXZ1PIVDOpv OyFzWWKcOrZjUIIusI/CT_GPM_2012_6 9.PDF>. Acesso em: 20/12/2012.

CANTINI, M. C. Políticas públicas e formação de professores na área de tecnologia de informação - TIC na rede pública estadual de ensino. 156 p. Dissertação (Mestrado em
Educação) - Pontifícia Universidade Católica do Paraná. Curitiba, 2008. Disponível em: <http://www.dominiopublico.gov.br/pesquisa /DetalheObraForm.do?select_action=\&co_o bra $=111213>$ Acesso em: 30/04/2012.DIA A DIA EDUCAÇÃO. Disponível em: 〈http://www.diaadia.pr.gov.br/index.php>.

Acesso em: 20/4/2012.

MOLINA, L. G. Tecnologias de informação e comunicação para gestão da informação e do conhecimento: proposta de uma estrutura tecnológica aplicada aos portais corporativos. In: VALENTIM, M. (Org.). Gestão, mediação e uso da informação. São Paulo: Cultura Acadêmica, 2010. p. 143-167.

PARANÁ. Secretaria de Estado da Educação. Um iceberg de possibilidades contra a exclusão sociodigital: a educação no Paraná no combate a desigualdade social realizando a inclusão digital da comunidade escolar. In:

Paraná digital: tecnologias de informação e comunicação nas escolas públicas paranaenses. Curitiba: SEED/PR, 2010. p. 65-115. Disponível em: <http://www.gestaoescolar.diaadia.pr.gov.br/ modules/conteudo/conteudo.php?conteudo =407>. Acesso em: 20/12/2012.

PORTAL Dia a Dia Educação, Secretaria de Estado da Educação do Paraná. Disponível em:<http://www.gestaoescolar.diaadia.pr.gov. br/modules/conteudo/conteudo.php?conteu do $=212>$. Acesso em: 8/7/2012.

SILVA, Â. C. Educação e tecnologia: entre o discurso e a prática. Ensaio: avaliação política pública educação, Rio de Janeiro, v. 19, n. 72, p. 527-554, jul./set. 2011.

SORDI, J. O. Administração da informação: fundamentos e práticas para uma nova gestão do conhecimento. São Paulo: Saraiva, 2009 .

TACHIZAWA, T.; ANDRADE, R. O. B. Tecnologias da informação aplicadas às instituições de ensino e às universidades corporativas. São Paulo: Atlas, 2003.

TONO, C. C. P. Do estado à escola em tempos de novas tecnologias na sociedade: papeis institucionais para o desenvolvimento. In: ALMEIDA, M. G.; FREITAS, M. C. D. (Org.). Atores responsáveis pela educação e seus papeis. Rio de Janeiro: Brasport, 2011. 


\section{ReLAInEP}

p.2-25. (A escola no século XXI, v. 1).

ZUCCARONE, M. A tecnologia de negócios para educação: educacional e-business. Salto, SP: Ed. Schoba, 2011. 